\title{
PtIr Microwire Bonding for Deep-Brain Microelectrode by Electroplating
}

\author{
Ge Qin, Yucheng Ding, Yaxiong Liu*, Hongzhong Liu and Jue Wang1 \\ State Key Laboratory for Manufacturing Systems Engineering, \\ Xi'an Jiaotong University, Xi'an 710049, P. R. China \\ ${ }^{1}$ Key Laboratory of Biomedical Information Engineering of Education Ministry, \\ Xi'an Jiaotong University, Xi'an 710049, P. R. China
}

(Received July 17, 2008; accepted March 16, 2009)

Key words: deep-brain microelectrode, microwire bonding, electroplating, tensile strength

Microelectrodes have been extensively implanted into patients' deep brain for longterm treatments of nervous system disorders, and Pt and PtIr are the preferred materials for the microelectrode film and microwire, respectively, because of their biocompatibility. A novel method of microwire bonding for connecting $\mathrm{Pt}_{90} \mathrm{Ir}_{10}$ microwires to the microelectrode is presented in this paper. After the microelectrode was fabricated through microelectromechanical systems (MEMS) techniques, the $\mathrm{Pt}_{90} \mathrm{Ir}_{10}$ microwire was connected to the microelectrode by electroplating Pt film on the microwires fixed on the connection pads of the microelectrode, instead of using a traditional bonding or soldering process. Optical photomicrography and scanning electron microscopy (SEM) revealed that the $\mathrm{Pt}_{90} \mathrm{Ir}_{10}$ microwire was connected tightly to the microelectrode by electroplating. The measured tensile strengths of the microwire connections reached up to $0.375 \mathrm{MPa}$ for the Pt film with a thickness of $3 \mu \mathrm{m}$ and above, and the maximum tensile force that the microwire $(75 \mu \mathrm{m}$ diameter) could withstand was about $1.6 \mathrm{~N}$. Experimental results indicated that the electroplating connection could provide sufficient strength for the microelectrode to accurately reach the target position in the deep brain.

\section{Introduction}

There is increasing interest in using microelectrodes to provide long-term treatments for nervous system disorders such as Parkinson's disease, blindness, deafness, paralysis and severe epilepsy. ${ }^{(1-5)}$ The microelectrodes lying in the target position of the deep brain record neural signals from a single neuron or clusters of neurons and provide electrical stimulating signals for disorder treatments. They are biocompatible for longterm treatment and sufficiently strong to be implanted into the deep brain. To avoid traumatizing tissue, the microelectrode should be fabricated small enough by advanced technology.

"Corresponding author: e-mail: yaxiongliu@163.com 
With the rapid development of MEMS technology in the biomedical field, micromachined devices with Si-based microelectrodes have become key components in implantable microsystems..$^{(5-7)}$ During the past decade, many and perhaps most types of implanted microelectrode structures and fabrication processes have been studied. ${ }^{(5-20)}$ Regarding the deep-brain microelectrode for long-term recording/stimulation, all the materials used to make the microelectrode must be biocompatible, and $\mathrm{Pt}$ and $\mathrm{Pt}_{90} \mathrm{Ir}_{10}$ alloy are the best materials for microelectrode films and microwires, respectively, because of their good biocompatibility and corrosion resistance and also because of the charge injection capacity of Pt and low impedance and good mechanical property of $\mathrm{Pt}_{90} \mathrm{Ir}_{10}$ alloy. ${ }^{(5,21)}$ As for the microelectrode, whether telemetry is used or not in the electrode system, communication between the implanted microelectrode and the outside stimulator must be carried out through a multichannel of interconnected microwires and a percutaneous connector. The mechanical and electrical stabilities of the connection are critical to the performance of the microelectrode system. In the above-mentioned references, microwire bonding was also studied and carried out by ultrasonic bonding, ${ }^{(5,9)}$ soldering, ${ }^{(13)}$ gluing with conductive epoxy ${ }^{(14,20)}$ or micromachining. ${ }^{(5)}$ However, owing to the high hardness and melting points of $\mathrm{Pt}$ and $\mathrm{Pt}_{90} \mathrm{Ir}_{10}$, it is difficult to connect $\mathrm{Pt}_{90} \mathrm{Ir}_{10}$ microwires to Pt thin film using the above joining methods. These conventional methods are unstable in terms of mechanical and electrical performances.

In this paper, we present a novel and effective bonding method for connecting $\mathrm{Pt}_{90} \mathrm{Ir}_{10}$ microwires with a Pt thin film on a Si-based deep-brain microelectrode by electroplating Pt film on the microwires fixed on the connection pads of the microelectrode. The microelectrode was fabricated by specific coating, wet etching, photolithography, and bulk micromachining technology, and was then connected to a $\mathrm{Pt}_{90} \mathrm{Ir}_{10}$ microwire by electroplating. The quality of the microwire bonding was examined by optical microscopy and scanning electron microscopy (SEM), and the strength of the microwire bonding was measured using a tensile strength tester. Experimental results were used to verify the feasibility of the proposed method.

\section{Materials and Methods}

\subsection{Materials}

One-hundred-millimeter-diameter 525 - $\mu \mathrm{m}$-thick $<100>$-oriented P-type silicon wafers were used as the substrate of the microelectrode. The $75-\mu$ m-diameter $\mathrm{Pt}_{90} \mathrm{Ir}_{10}$ microwires coated with 30- $\mu$ m-thick polypropylene, which are the materials suitable for the implantable deep-brain microelectrode for long-term treatment, were purchased from A-M Systems Inc. Electrolyte solutions were freshly prepared with double-distilled water, and deoxygenation was achieved with a stream of argon for 5 min prior to the electroplating experiments. All the chemicals used in this study were of analytical grade; all the materials in the implanted part of the microelectrode were medical grade, and the experiments were performed at room temperature. 


\subsection{Si-based Pt microelectrode}

Using standard single-side-polished 4-inch silicon wafers as substrate, we began the fabrication of the microelectrode by CVD to deposit lower dielectric layers of $\mathrm{SiO}_{2}(500 \mathrm{~nm})$ to insulate the recording/stimulation layer from the silicon substrate. After the photoresist was spin-coated and patterned, the recording/stimulation layer and conductive film, Ti/Pt $(20 \mathrm{~nm} / 200 \mathrm{~nm})$, were deposited and patterned by RF magnetron sputtering and metal lift-off procedure and then insulated with $\mathrm{SiO}_{2}$ film by low-temperature plasma-enhanced chemical vapor deposition (PECVD). In the last procedure, the recording/stimulation and connecting sites were exposed by wet etching. Figure 1 is an optical photomicrograph of the micromachined microelectrode. It also enabled the design of double-side planar microelectrodes with specific site configuration and physical layout customized according to the targeted neural structure.

After the Si-based Pt microelectrode is fabricated, the microwires are connected to the microelectrode by electroplating (Fig. 2), in our next work, the Si-based Pt microelectrode will be encapsulated into a cylinder with polyurethane to avoid traumatizing brain tissue. The encapsulated microelectrode and part of the microwire lead will be implanted into the deep brain to record the neural signals of the target and stimulate the target, and a percutaneous connector is used to connect the microwire to the outside stimulator.

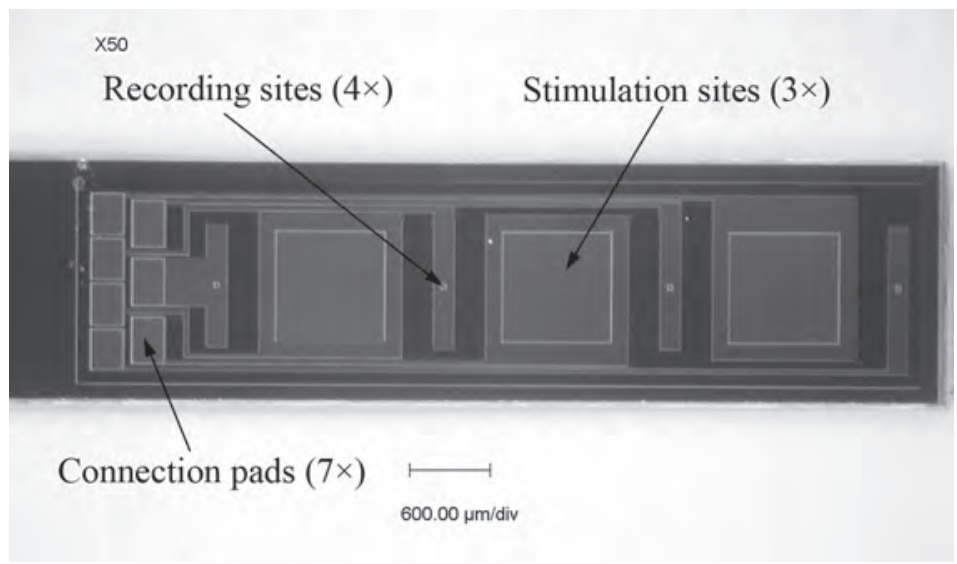

Fig. 1. Optical photomicrograph of Si-based Pt film microelectrode, which consists of an array of three stimulation sites $\left(800 \times 800 \mu \mathrm{m}^{2}\right)$ and four recording sites $\left(20 \times 20 \mu \mathrm{m}^{2}\right)$, and there are seven connection pads of the end of the microelectrode.

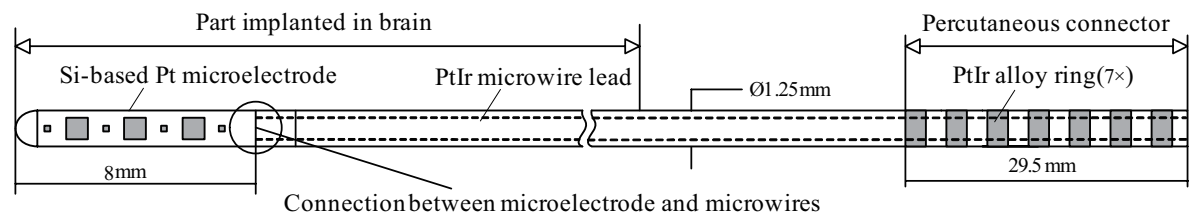

Fig. 2. Schematic diagram of deep-brain microelectrode system. 


\subsection{Microwire bonding of microelectrode}

The connection between micromachined devices and the macrocosm depends on the application, environment, and microelectrode design. Ultrasonic bonding is the preferred method of connecting the microdevices to the macrocosm. The wire materials of bonding, such as $\mathrm{Au}, \mathrm{Cu}$ or $\mathrm{Si}-\mathrm{Al}$, which must have low hardness and melting point, can be heated into their molten state and then pressed onto the film very easily. These materials, however, are unsuitable for the deep-brain microelectrode used in long-term treatment, and the PtIr alloy is a suitable wire material for this type of microelectrode. However, it is difficult for the $\mathrm{Pt}_{90} \mathrm{Ir}_{10}$ wire to be bonded onto a Pt film because of its high hardness and melting point (Fig. 3(a)). Furthermore, welding processes such as laser welding are also unsuitable for this connection because the thermal expansion coefficients of the Pt film and silicon substrate are different, and the shrinkage of the $\mathrm{Pt}$ film is different from that of the substrate, which results in the wrinkling and cracking of the Pt film layer in the heat-affected zone after the Pt film is heated to a molten state (Fig. 3 (b)). In addition, resistance spot-welding is attempted to connect the $\mathrm{Pt}_{90} \mathrm{Ir}_{10}$ microwires to the microelectrode, but the bonding strength is very low. In ref. (9), it was proposed that wires of a standard 80-conductor computer cable should be soldered directly onto the Pt pads with a solder flux. This is a feasible method for a white mouse's implant because the solder region is outside the brain and it is not necessary that the material of the solder region be biocompatible; however, the soldering is unsuitable for the microwire connection of the deep-brain microelectrode used here because of the poor biocompatibility of its
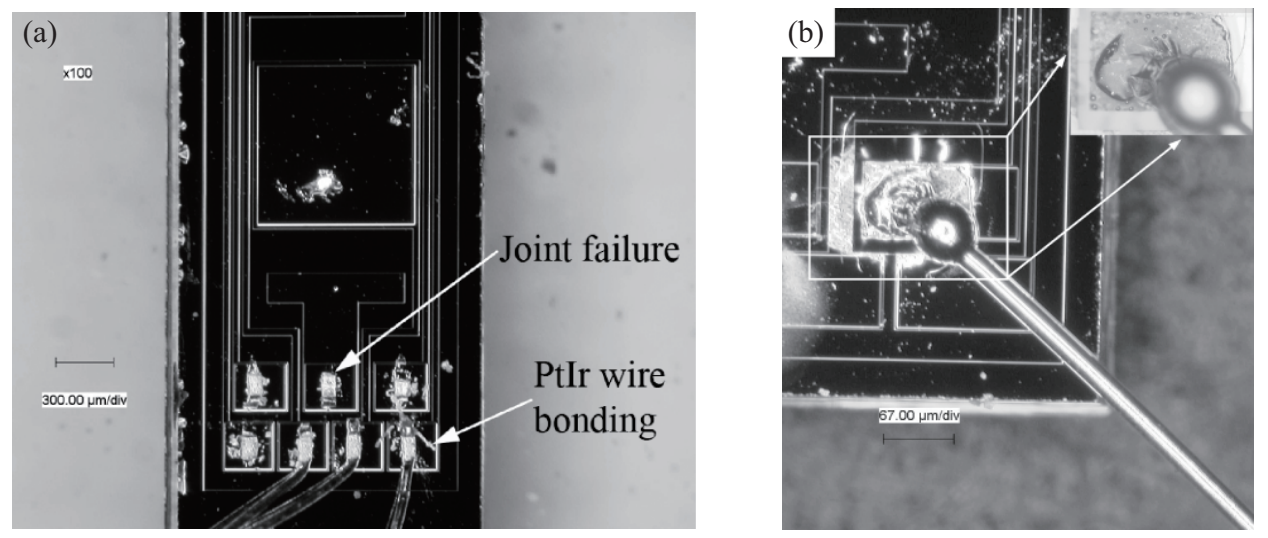

Fig. 3. Optical photomicrograph of the $\mathrm{Pt}_{90} \mathrm{Ir}_{10}$ wire ultrasonic bonding (a) and the laser welding connection (b). The strength of the bonding connection is less than $0.1 \mathrm{~N}$, and the failure rate of the $\mathrm{Pt}_{90} \mathrm{Ir}_{10}$ wire bonding on the $\mathrm{Pt}$ film is higher than $95 \%$. In laser welding, the film in the heataffected zone is wrinkled and compromised by the laser energy, and the electric resistance of the laser joint reached up to $(30 \pm 5) \mathrm{k} \Omega$, which is considered as the failure of the electric circuit for the microelectrode system. 
solder flux. The above difficulties are challenges faced by researchers attempting to develop new PtIr microwire bonding processes.

However, we observed an interesting phenomenon by accident, that is, an electroplated metal film could be used to glue a microwire on the work surface in the electroplating process. The electroplating process is analyzed in Fig. 4. Figure 4(b) shows that electroplated metal molecules are first crystallized on the surface of the seed layer and microwire, and then grow vertically on the surfaces. When the molecules electroplated on the seed layer meet the molecules on the microwire, the electroplated metal grows upward and the microwire connection is implemented (Fig. 4(c)). The microwire should be fixed tightly onto the seed layer with a special holder during the electroplating; otherwise, the failure of connection would occur.

The connection strength can be determined on the basis of the design and method of the connection. In this study, finite-element analysis (FEA) software (COMSOL Multiphysics 3.0, COMSOL Inc., Burlington, MA) was used to determine the stress distribution of three microwire connection patterns: i.e., vertical connection (the bonding connection), angle connection (the welding or bonding connection), and level connection (the electroplating connection) (Figs. 5(a)-(c)). All the microwires were of the same size $(0.2 \mathrm{~mm}$ diameter, $3 \mathrm{~mm}$ length). In surgery, the insertion force distributed at the connection position is parallel to the microelectrode substrate, so a level load (100 N) parallel to the substrate was applied at the end of the connected wire. Figures 5(d) -(f) revealed that the stress of the electroplating connection was lowest in the three connection modes under the same load, which was due to only tensile stress in this connection and the largest contacting area between the microwire and substrate. The results showed that electroplating was an optimal connection process and it could provide sufficient strength for the microelectrode to penetrate the cerebral cortex and tissue of the deep brain.
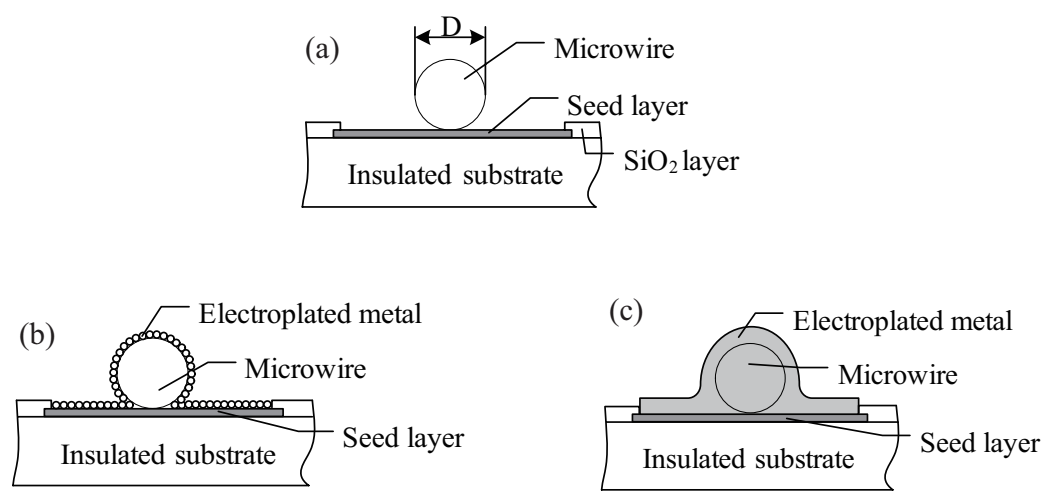

Fig. 4. Schematic of microwire's electroplating process: before electroplating (a), during electroplating (b), after electroplating (c). The materials of seed layer, microwire and electroplated metal are $\mathrm{Pt}, \mathrm{Pt}_{90} \mathrm{Ir}_{10}$ and $\mathrm{Pt}$, respectively. 

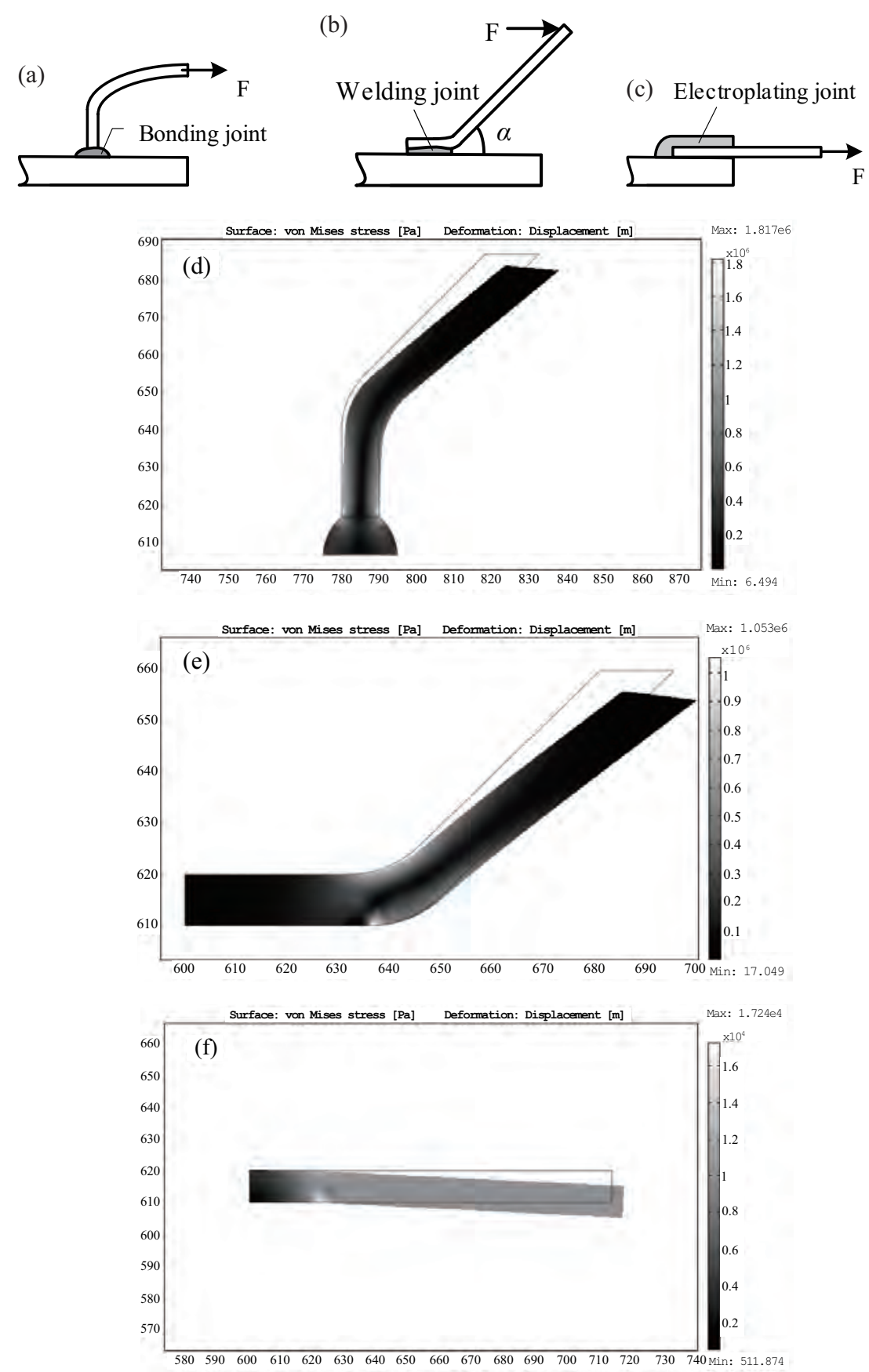

Fig. 5. Schematic of microwire stress analysis for different microwire bondings and von Mises stress and deflection $(L=3 \mathrm{~mm}, D=0.2 \mathrm{~mm}$, Load force $=100 \mathrm{~N}$ ): ultrasonic bonding (a) and (d), welding or bonding (b) and (e), and electroplating (c) and (f). 
The electroplating process for connecting the microwires to the microelectrode is demonstrated. Figure 6 shows schematically the electroplating process. We employed an alkaline solution because of its high current efficiency in electroplating. The electrolyte for electroplating $\mathrm{Pt}$ is composed of $20 \mathrm{~g} / \mathrm{L}$ chloroplatinic acid $\left(\mathrm{H}_{2} \mathrm{PtC}_{16}\right)$, $40 \mathrm{~g} / \mathrm{L}$ potassium hydroxide, and $5 \mathrm{mg} / \mathrm{L}$ calcium chloride. Before electroplating, the 75 - $\mu$ m-diameter $\mathrm{Pt}_{90} \mathrm{Ir}_{10}$ microwire was fixed tightly onto the connection pad of the microelectrode using a special holder, and then the end of the microelectrode was inserted in the plating bath. The electroplating was carried out at a constant current of the potentiostat (Model HDV-7C, Fujian Sanming, China) with the microwire as the cathode and a $3 \times 3 \mathrm{~cm}^{2} \mathrm{Pt}$ plate as the anode. A current density of $3 \mathrm{~A} / \mathrm{dm}^{2}$ was used to electroplate about $15 \mu \mathrm{m}$ of $\mathrm{Pt}$ in $2 \mathrm{~h}$. The morphologies of the electroplating connection were examined by optical microscopy (VH-8000, Keyence Ltd., Japan) and SEM (CABL-9000C, Crestec Ltd., Japan), and the strength of the electroplating connection was measured with a tensile strength tester.

\section{Results and Discussion}

\subsection{Characterization of microwire bonding}

The microwire bonding of the microelectrode was performed by electroplating the Pt film onto the microwires fixed on the connection pads of the microelectrode. Figures 7(a)-(c) show that the electroplated Pt film tightly connected the microwire and the pad on the microelectrode, and there were no obvious gaps inside the electroplated layer (Fig. 7(c)). The measured Pt thin film was about $15 \mu \mathrm{m}$ in thickness. The magnified view of the electroplated Pt film revealed a rough surface and some microcracks (Figs. $7(b)$ and $7(d)$ ). For measuring the strength, the connection was broken and the tensile failure of the connection appeared at the microwire connection interface instead of at any other positions of the microwire connection (Fig. 7(d)). This result showed that the strength of the electroplated interface was lower than that of the other positions on the microwire connection, and the microdefects on the electroplated film had no effect on the connection strength.

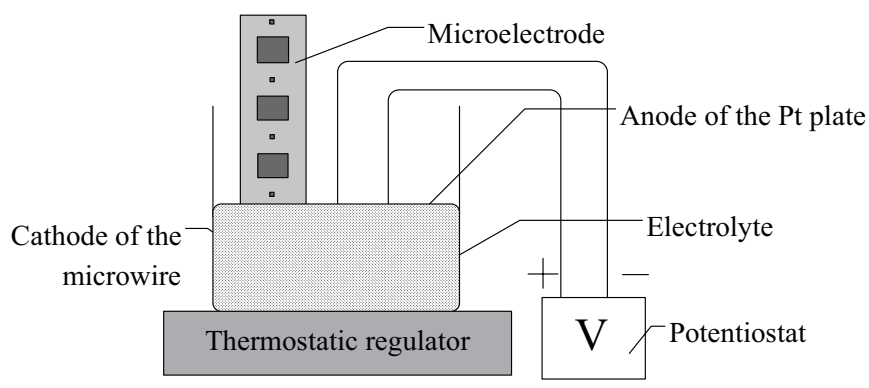

Fig. 6. Schematic of electroplating process. The microwire fixed on the connection pad of the microelectrode was the cathode, the Pt piece $\left(3 \times 3 \mathrm{~cm}^{2}\right)$ was the anode. The electroplating temperature was maintained at $80^{\circ} \mathrm{C}$, and the $\mathrm{PH}$ of the electrolyte was adjusted to 13.5 using ammonia. 

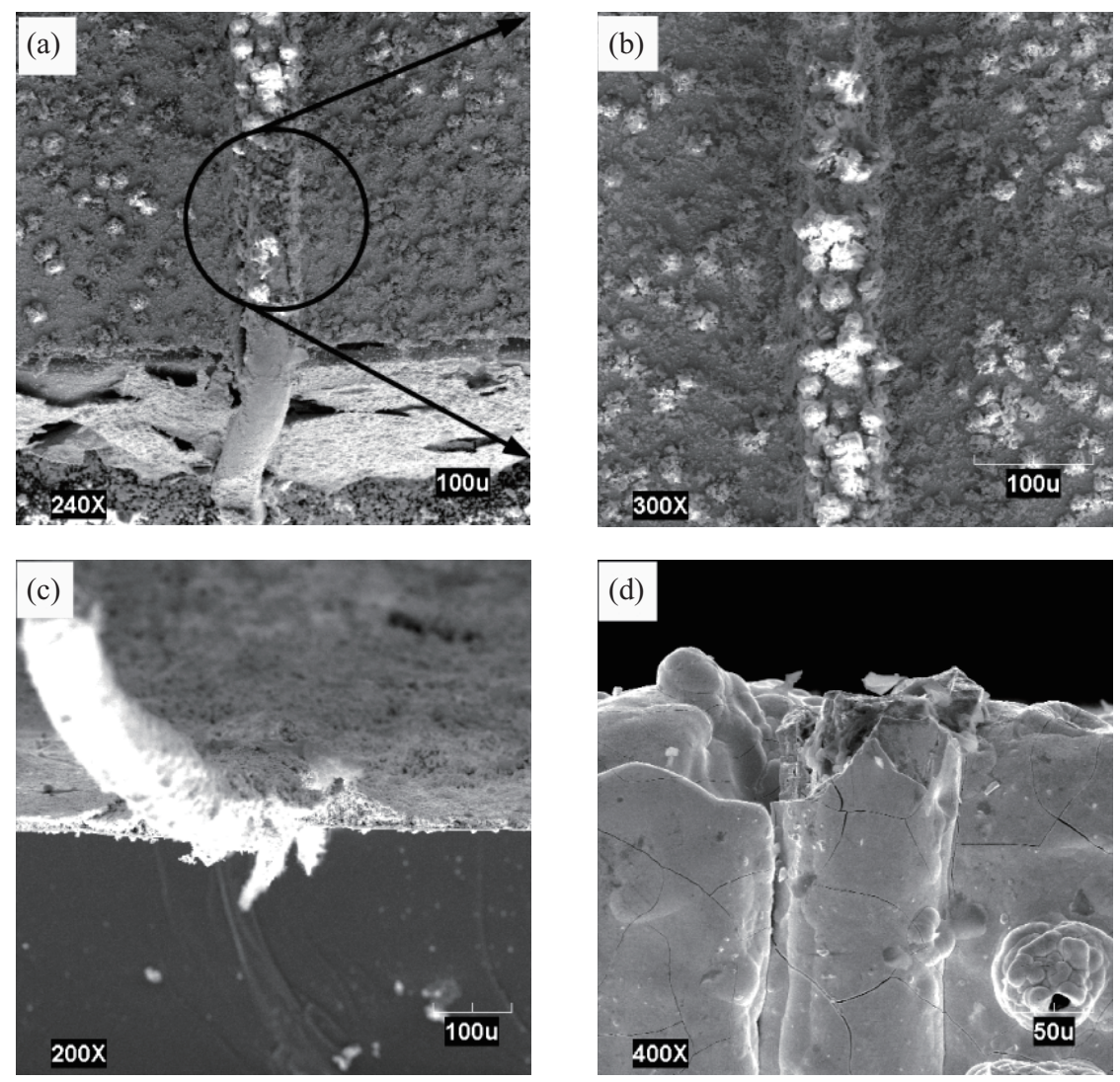

Fig. 7. SEM images of the microwire bonding using electroplating (a) and (b), the cross section of the wire connection (c), and the fractured surface of the connection (d). The fractured site was at the interface of the wire connection after measuring the strength of the connection to the microwire ( $75 \mu \mathrm{m}$ diameter).

\subsection{Tensile strength of the electroplating connection}

In surgery, the encapsulated microelectrode has to be inserted into the brain and will bear a push force acting on the center line of the microelectrode, and the forces acting on the connection site are the tensile and shear forces. Because the shear force is very small and can be neglected, the strength and reliability of the electroplating connection were measured using a tensile strength tester. The results demonstrated that a connected microwire could withstand $1.6 \mathrm{~N}$ tension for the electroplated Pt film $(15 \mu \mathrm{m})$. The tensile strength of $\mathrm{Pt}_{90} \mathrm{Ir}_{10}$ alloy is $0.357 \mathrm{MPa}$ and the maximum tensile force that the microwire ( $75 \mu \mathrm{m}$ diameter) can withstand is about $1.6 \mathrm{~N}$. Thus, it could be concluded that the strength of the microwire connection was higher than that of the microwire. Therefore, it was possible that seven microwire connections could withstand 


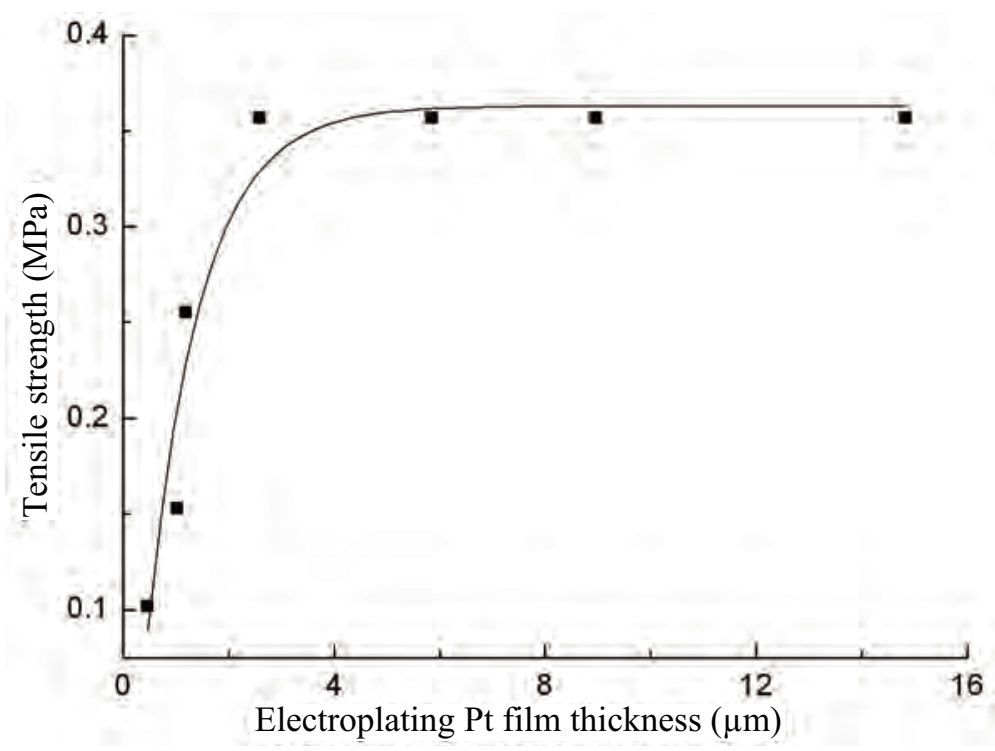

Fig. 8. Effect of electroplated Pt film thickness on the tensile strength of microwire connection.

a tensile force higher than $1.6 \mathrm{~N}$. Furthermore, the strength of the microelectrode after encapsulation will be enhanced to higher than $1.6 \mathrm{~N}$ because the encapsulation protects the microwire connection. In refs. (9) and (14), an average insertion force of less than $0.25 \mathrm{~N}$ was used, so these connections had sufficient strength to withstand the insertion force used in surgery. In Fig. 8, the increase in tensile strength for the microwire connection was observed with the thickness of the electroplated Pt film. The tensile strength increased more quickly with the film thickness when it was in the range of 0.2 $-3 \mu \mathrm{m}$, while the tensile strength reached up to $0.375 \mathrm{MPa}$ and remained constant with the increase in the film thickness above $3 \mu \mathrm{m}$, which was considered as the maximum tensile strength that the microwire connection could withstand. It will be discussed that how much particular force is generated at the connection part during the penetration after encapsulation in our next work.

\section{Conclusions}

The Si-based Pt film microelectrode for treating nervous system disorders in the deep brain was fabricated by MEMS techniques, and electroplating was carried out to connect the microwire to the microelectrode. Optical photomicrography and SEM revealed that the microwire was tightly connected to the microelectrode by electroplating. When the thickness of the electroplated Pt film was above $3 \mu \mathrm{m}$, the strength of the electroplating connections reached up to $0.375 \mathrm{MPa}$, which is the maximum strength of the $\mathrm{Pt}_{90} \mathrm{Ir}_{10}$ microwire. The strength of the microwire $(75 \mu \mathrm{m}$ diameter) connection was $1.6 \mathrm{~N}$ for 
the electroplated film thickness above $3 \mu \mathrm{m}$, which showed that these electroplated connections had sufficient strength to withstand the insertion force used in surgery. The results indicated that electroplating could be used as an effective method of connecting $\mathrm{Pt}_{90} \mathrm{Ir}_{10}$ microwires to the deep-brain microelectrode for long-term use.

\section{Acknowledgements}

Financial support from the National Hi-Tech Program of China (Grant No. 2006AA04Z370) and the National Natural Science Funds (Grant Nos. 50775176 and 50505037) is acknowledged. The authors would like to thank Professor Yiping Tang of the State Key Laboratory for Manufacturing Systems Engineering, and the Institute of Microelectronics of Peking University and Key Laboratory of Analytical Chemistry for Life Science of Shaanxi Normal University for valuable technical assistance.

\section{References}

1 D. Tarsy: Epilepsy Behav. 2 (2001) S45.

2 D. E. Hardesty and H. A. Sackeim: Biol. Psychiatry 61 (2007) 831.

3 A. L. Benabid, G. Deuschl, A. E. Lang, K. E. Lyons and R. Rezai: Movement Disord. 21 (2006) S168.

4 M. Lozano: Parkinsonism Relat. Disord. 7 (2001) 199.

5 K. D. Wise, D. J. Anderson, J. F. Hetke, D. R. Kipke and K. Najafi: P IEEE 1 (2004) 76.

6 M. P. Lepselter: Bell Syst. Tech. J. 45 (1966) 233.

7 K. D. Wise and J. B. Angell: IEEE Trans. Biomed. Eng. 22 (1975) 212.

8 D. R. Kipke, R. J. Vetter, J. C. Williams and J. F. Hetke: IEEE T. Neur. Sys. Reh. 11 (2003) 151.

9 S. Snow, S. C. Jacobsen, D. L. Wells and K. W. Horch: IEEE Trans. Biomed. Eng. 53 (2006) 320.

10 C. Moldovan, V. Ilian, G. Constantin, R. Iosub, M. Modreanu, I. Dinoiu, B. Firtat and C. Voitincu: Sens. Actuators, A 99 (2002) 119.

11 T. Stieglitz and M. Gross: Sens. Actuators, B 83 (2002) 8.

12 M. Gross, D. Altpeter, T. Stieglitz, M. Schuettler and J. Meyer: Sens. Actuators, A 96 (2002) 105.

13 P. S. Motta and J. W. Judy: IEEE Trans. Biomed. Eng. 52 (2005) 923.

14 J. Muthuswamy, M. Okandan and N. Jackson: J. Neurosci. Methods 142 (2005) 45.

15 J. W. Liu, C. Bian, J. H. Han, S. F. Chen and S. H. Xia: Sens. Actuators, B 106 (2005) 591.

16 J. D. Kralik, D. F. Dimitrov, D. J. Krupa, D. B. Katz, D. Cohen and M. A. Nicolelis: Methods 25 (2001) 121.

17 P. K. Campbell, K. E. Jones, R. J. Huber, K. W. Horch and R. A. Normann: IEEE Trans. Biomed. Eng. 38 (1991) 758.

18 P. J. Rousche, D. S. Pellinen, D. P. Pivin, J. C. Williams, R. J. Vetter and D. R. Kipke: IEEE Trans. Biomed. Eng. 48 (2001) 361.

19 D. Lowinsohn, H. E. M. Peres, L. Kosminsky, T. R. L. C. Paixão, T. L. Ferreira, F. J. Ramirez-Fenandez and M. Bertotti: Sens. Actuators, B 113 (2006) 80.

20 J. H. Lee, A. Jang, P. R. Bhadri, R. R. Myers, W. Timmons, F. R. Beyette, P. L. Bishop and I. Papautsky: Sens. Actuators, B 115 (2006) 220.

21 L. A. Geddes and R. Roeder: Ann. Biomed. Eng. 31 (2003) 879. 